\title{
Molecular Characterization of Solanum Species (Solanum aethiopicum complex; Solanum macrocarpon and Solanum anguivi) Using Multiplex RAPD primers
}

\author{
C. U. Aguoru ${ }^{1}$, L. O. Omoigui ${ }^{2} \&$ J. O. Olasan ${ }^{1}$ \\ ${ }^{1}$ Department of Biological Sciences, University of Agriculture, Makurdi, Nigeria \\ ${ }^{2}$ Department of Plant breeding and Seed Science, University of Agriculture, Makurdi, Nigeria \\ Correspondence: C. U. Aguoru, Department of Biological Sciences, University of Agriculture, Makurdi, Nigeria. \\ E-mail: celeaguoru@yahoo.com
}

Received: December 26, $2014 \quad$ Accepted: January 23, $2015 \quad$ Online Published: February 1, 2015
doi:10.5539/jps.v4n1p27
URL: http://dx.doi.org/10.5539/jps.v4n1p27

\begin{abstract}
Genetic diversity of $S$. aethiopicum complex, $S$. macrocarpon and $S$. anguivi was investigated using molecular approach. Seeds were randomly secured across north central locations in Nigeria and planted. Nine (9) oligonucleotide primers were initially screened for their polymorphism from where five (5) polymorphic primers were selected. A total of twenty five (25) accessions were studied. DNA was extracted from each accession using FTA PlantSaver card method following standard protocol (Whatman ${ }^{\circledR}, 2014$ ). Amplification of the extracted DNA was performed on a thermal cycler (Applied Biosystem in Life Technology version 2720) through the use of a multiplex of OPP-11, B-18, OPU-13 and OPU-15 primers. A total of fifty (50) PCR reactions were carried out (25 separate reactions each for OPQ-07 primer and Multiplex primer). Amplified products were resolved on agarose gel electrophoresis. DNA band profiles generated by primers were manually scored (using zero (0) for absence of band and one (1) for presence of band) to generate binary matrices for the two band profiles. Statistical analysis was performed using the SPSS (Statistical Package for Social Scientists) software (20.0 Version). Hierarchical cluster analysis of all the individual accessions was done using the Average Linkage "Between Group" Method based on Euclidean Distance measurement, to generate two dendrograms, one for each primer set. Results revealed the polymorphic strength of each primer sets as $45 \%$. Each primer yielded an average of 4.5 polymorphic loci per 10 DNA bands. Dendrograms showed high level of intraspecific and interspecific variability and similarities among the accessions whose clustering patterns were both location dependent and location independent. Based on the clustering patterns, there were sharp genetic dissimilarities between $S$. aethiopicum gilo, $S$. anguivi medium, $S$. anguivi tiny, striped gilo-kumba complex and S. macrocarpon on one hand, and similarities among the species on the other hand indicating a common ancestral origin. Having established a substantial level of variability in this study, breeding efforts of varieties may be facilitated for improvement programme and this can also be used as a template for further taxonomic studies of the unidentified seeds and fruits showing divergent characters.
\end{abstract}

Keywords: multiplex primer, PCR premix, diversity, cluster, taxonomy, crop improvement

\section{Introduction}

The Genus Solanum belongs to the family Solanaceae, a large family which has been the source of many morphologically different domesticated species (Sharmin et al., 2011). About 2300 species have been identified in this family, nearly one-half of which belong to the genus Solanum (Agnieszka et al., 2007). A detailed taxonomic audit of the genus Solanum was reported by Agnieszka et al. (2007). According to these authors, the common name 'eggplant' encompasses three closely related cultivated species, endemic to Africa, belonging to the genus Solanum L., subgenus Leptostemonum (Dunal) Bitter. Two Sections exist in this subgenus namely: Section Melongena and Section Oliganthes. The former comprises two species namely: S. melongena and S. macrocarpon while the latter Section has only one species named S.aethiopicum. This species is further grouped into different ecotypes which are; Aculeatum, Gilo, Kumba and Shum group as revealed by similarities in genotypic characterization though varied phenotypes exist (Sharmin et al., 2011). However, some authors have argued that the four groups in S.aethiopicum be treated as different species since they all display varied 
phenotypes and genotypes using a combination of molecular markers (Nunome et al., 2001; Sifau et al., 2014 ). Apart from the four species stated above, taxonomists have also identified and reported other Solanum species including S. incanum, S. scabrum, S. dasyphyllum and S. erianthum (Agnieszka et al., 2007; Osei et al., 2010; Knapp et al., 2013; Mariola et al., 2014; Sifau et al., 2014) while many species are yet to be identified, named and classified systematically (Agnieszka et al., 2007). The various species are known for their ethnobotanical uses most especially as food and trado-medicine.

Due to the effect of heterosis emanating from natural hybridization and backcrossing occurring in the crop coupled with species' wide ecogeographical distribution, the variability in the crop is enormous (Oyelana \& Ugborogho, 2008). Therefore, there is need for a continuous systematic audit of the crop which may solve taxonomic problems and give directions to plant breeders when categorizing their germplasm. Despite the widespread cultivation and nutritional and economic importance of eggplants, their genome has not yet been extensively evaluated as done on other solanaceous vegetables such as tomato, potato and pepper (Demir et al., 2010). Holistically, few studies have been performed to determine the genetic diversity of eggplant using molecular markers. RAPD (Random Amplified Polymorphic DNA) marker was singly used by Nunome et al. (2001); Demir et al. (2010), Sharmin et al. (2011) and Sifau et al. (2014). Other markers that have so far been used singly or in combined forms include but not limited to the following: AFLP (Amplified Fragment Length Polymorphism) (Mace et al., 1999); RAPD and AFLP (Nunome et al., 2001); SSR (Simple Sequence Repeats) (Nunome et al., 2003; Khorsheduzzaman et al., 2008; Stagel et al., 2008; Hurtado et al., 2012); SSR and RAPD (Demir et al., 2010) and ISSR (Inter Simple Sequence Repeats) (Isshiki et al., 2008; Mahmoud \& El-Mansy, 2012).

Therefore, proper classification of eggplant cultivars collected all over the world is possible to achieve with the use of molecular approach. This may be supplemented with other sources of taxonomic evidence (Agnieszka et al., 2007; Oyelana \& Ugborogho, 2008; Shalom et al., 2011; Hurtado et al., 2012). The use of molecular markers in eggplant diversity studies has thrown green light into the taxonomic darkness of the crop. Generally, the detection of substantial level of polymorphism using RAPD has attracted the attention of plant taxonomists and plant breeders all over the world because of its simplicity and rapidity (Sifau et al., 2014). Molecular characterization of eggplant using marker approach is generally limited in Nigeria. The aim of this study was therefore to employ the use of RAPD molecular marker to reveal taxonomic relationship and assess the diversity of three species of eggplant in the North central axis of Nigeria.

\section{Materials and Methods}

Seeds of eggplant species were randomly secured from ripe fruits and markets across north central locations in Nigeria (Table 1) and planted in the research farm of the University of Agriculture, Makurdi. Nine (9) procured oligonucleotide primers (Inqaba Inc. South Africa, 2014) were screened for their polymorphism by employing each primer in the amplification of nine (9) different DNA samples from where five (5) polymorphic primers were selected. A total of twenty five (25) accessions were studied. DNA was extracted from each accession using FTA PlantSaver card method following standard protocol (Whatman ${ }^{\circledR}, 2014$ ). Amplification of the extracted DNA was performed on a thermal cycler (Applied Biosystem in Life Technology version 2720) through the use of a multiplex primer that combines the polymorphic strength of the selected OPP-11, B-18, OPU-13 and OPU-15 primers. Fifty (50) PCR reactions were carried out using conventional PCR and Multiplex PCR techniques (25 separate reactions each for OPQ-07 primer and Multiplex primer respectively). For each PCR reaction mixture, one (1) washed FTA disc (contained the DNA template), $18 \mu 1$ of molecular water and $1 \mu 1$ of one specific primer pair were mixed in a PCR tube already containing a customized BIONEER ${ }^{\circledR}$ Accupower PCR Premix to make a total of $20 \mu 1$ as the reaction volume. The PCR tubes were loaded on the thermal cycler and programmed with the appropriate temperature profile following the method of Sifau et al. (2014). The amplified DNA sample in each tube was dispensed into an agarose gel pore inside an electrophoresis tank connected to Consort EV243 electrophoresis power supply. DNAs were allowed to be resolved for one hour and viewed in an illuminating chamber. DNA band profile generated by each primer was manually scored (using zero (0) for absence of band and one (1) for presence of band) to generate binary matrices for the two band profiles. Statistically analysis was performed using the SPSS (Statistical Package for Social Scientists) software (20.0 Version). Hierarchical cluster analysis of all the individual accessions was done using the Average Linkage "Between Group" Method based on Euclidean Distance measurement, to generate two dendrograms. 
Table 1. Eggplant locations of collection

\begin{tabular}{|c|c|c|c|c|c|}
\hline STATE & LOCATION NAME & LOCATION TYPE & SAMPLE TYPE & SPECIES & ACCESSION CODE \\
\hline NASARAWA & Orange market Mararaba & Market & Dry seed & Seed collection & NS1C \\
\hline NASARAWA & Autabalefi & Farm & Ripe fruit & Unidentified & NS2C \\
\hline NASARAWA & Ado & Home garden & Ripe fruit & S.aethiopicum Gilo & NS3B \\
\hline NASARAWA & Keffi (after NYSC camp) & Farm & Ripe fruit & S.aethiopicum Gilo & NS5 \\
\hline KOGI & Yagba West & Farm & Ripe fruit & S.aethiopicum Gilo & KG1A \\
\hline KOGI & Kabba Bunnu & Farm & Ripe fruit & Unidentified & KG2C \\
\hline KOGI & Anyigba & Market & Dry seed & Seed collection & KG4 \\
\hline KOGI & Asaya & Farm & Ripe fruit & S.macrocarpon & KG6 \\
\hline BENUE & $\mathrm{Tomu} / \mathrm{Mu}$ & Farm & Ripe fruit & Striped Gilo-Kumba complex & BN1A \\
\hline BENUE & NorthBank & Market & Dry seed & Seed collection & BN3B \\
\hline BENUE & Nyiongu & Home garden & Ripe fruit & S.macrocarpon & BN6 \\
\hline BENUE & Welfare quarters & Home garden & Ripe fruit & S.anguivi tiny & BN7 \\
\hline BENUE & Uniagric & Farm & Ripe fruit & S.aethiopicum Gilo & BN8 \\
\hline FCT & Karshi & Farm & Ripe fruit & S.aethiopicum Kumba & FCT2 \\
\hline FCT & Kurudu & Home garden & Ripe fruit & S.aethiopicum Kumba & FCT3 \\
\hline FCT & Kwali (before NMC) & Farm & Ripe fruit & S.aethiopicum Gilo & FCT5 \\
\hline FCT & Lugbe & Home garden & Ripe fruit & S.aethiopicum Gilo & FCT6 \\
\hline NIGER & Suleja & Market & Dry seed & Seed collection & NG1B \\
\hline NIGER & Suleja & Market & Dry seed & Seed collection & NG1C \\
\hline NIGER & Mandalla & Farm & Ripe fruit & S.anguivi medium & NG2A \\
\hline NIGER & Minna road & Farm & Ripe fruit & S.aethiopicum Gilo & NG3C \\
\hline PLATEAU & Gimi & Farm & Ripe fruit & S.aethiopicum Gilo & PL1A \\
\hline PLATEAU & Riyom & Farm & Ripe fruit & Unidentified & PL2B \\
\hline PLATEAU & Maraban Jamaa & Farm & Ripe fruit & S.aethiopicum Gilo & PL3 \\
\hline PLATEAU & Hoss & Farm & Ripe fruit & S.anguivi medium & PL4A \\
\hline
\end{tabular}

\section{Results and Discussion}

The earlier use of RAPD markers as a rapid technique of revealing intraspecific and interspecific polymorphisms in eggplant (Nunome et al., 2001; Demir et al., 2010; Sharmin et al., 2011; Sifau et al., 2014) has been successfully established in this study.

The DNA band profile generated by the multiplex primer (Figure 1) is unique. A sharp band common to all the accessions on locus number 5 is an indication of convergence of a particular character coded for by the conserved gene at that particular spot (Agnieszka et al., 2007). Hence, the genomics in genus Solanum are evolving at a moderate pace compared to other plant species based on the findings of Doganlar et al. (2002a) as cited by Agnieszka et al. (2007). The strength of the RAPD primer used in revealing polymorphism shows that each of OPQ-07 and multiplex primer was averagely polymorphic by $45 \%$ yielding an average of 4.5 polymorphic bands per 10 DNA bands (Table 2). This result contrasts the findings of Sifau et al. (2014) who reported $69-83 \%$ polymorphic strength in the RAPD primers used in Southwest Nigeria. Meanwhile, it also disagrees with the findings of some authors (Smulders et al., 1997; Nunome et al., 2003; Stagel et al., 2008) who reported very low frequency of polymorphism in their primers. However, it is in resonance with report of Demir et al. (2010) who employed the use of two different markers, SSR and RAPD markers in the assessment of genetic diversity of Solanum melongena germplasm in Turkey where average genetic polymorphism was reported in the primers. 
The information revealed by the two dendrograms are complimentary. Dendrogram of OPQ- 07 primer (Figure 2) consists of 1 main cluster grouped into three sub clusters. Clustering is not based on location except in KG2C and $\mathrm{KG} 6$ as well as BN3B and BN8 that showed affinity to their location.Other sub clusters are location independent: NG2A (S. anguivi medium), PL4A (S. anguivi medium) and BN1A (Striped Gilo-Kumba complex) were clustered together. This shows a relationship of commom progenitor between $S$. anguivi medium and hybrid of $S$. aethiopicum gilo and kumba group. BN6 (S. macrocarpon and PL1A (S. aethiopicum gilo) and NS5 (S. aethiopicum gilo) are separately converged together, therefore showing close relatedness between $S$. macrocarpon and $S$. aethiopicum gilo. Divergence was observed in FCT 2 (S. aethiopicum Kumba), FCT 5 (S. aethiopicum Gilo), BN 7 (S. anguivi tiny), PL2B (unidentified fruit from Riyom Jos) and NS 1C (seeds collected from orange market Nasarawa) showing no close relationship with others. PL3 (S. aethiopicum Gilo) and NS2C (unidentified fruit from Autabalefi Nasarawa) were highly unclustered. Based on this information PL3 and NS2C accessions are genetically different from other accessions. This agrees with authors (Nunome et al., 2001; Sifau et al., 2014) who suggested that S.aethiopicum gilo be classified as a separate species of from the rest of S.aethiopicum group and be named $S$. gilo. NS2C could not be identified because of the unique characteristics of the ripe fruits making identification difficult.

Dendrogram of multiplex primer (Figure 3) gave 2 clusters whose clustering pattern could be described as highly divergent. Among all the accessions, clustering did not show any relationship with geographical locations except those from the FCT and few others. There are lots similarities and differences among the accessions. Some accessions are noted for their divergence including PL4A (S. anguivi medium), BN8 (S. aethiopicum Gilo), KG6 (S. macrocarpon), PL3 (S. aethiopicum Gilo), BN7 (S. anguivi tiny) and BNIA (Striped Gilo-Kumba complex). The information from the multiplex dendrogram has therefore substantiated that of OPQ-07 primer that the above species are genetically different. The two $S$. aethiopicum gilo above may be seen as different varieties of $S$. gilo since this group is now suggested to be a separate species different from the kumba and shum group. The striped gilo-kumba complex has consistently displayed varied genotypes as well.

Clustering pattern of the two dendrograms therefore corroborates the report of Lester (1998) that that $S$. aethiopicum was domesticated in Africa from its wild relative S. anguivi. Similarly, this outcome is in agreement with the results of Karihaloo et al. (2002) who used seed protein study and those of Furini and Wunder (2003) who adopted AFLP markers to establish that $S$. macrocarpon is related to $S$. aethiopicum. Similar results were obtained by Mace et al. (1999) based on the AFLP analysis of genetic relationship among the cultivated eggplants and wild relatives. The authors confirmed the close relationship between $S$. dasyphyllum, S. macrocarpon and S. aethiopicum. In their analysis, the fact that the last two of these species are domesticated and cultivated mainly in Africa supports their relatively similar topology in the dendrogram. This finding has aligned with the taxonomic review of Agnieszka et al. (2007) that the genus Solanum has been a source of many morphologically and genetically different domesticated species sharing similar ancestral characteristics.

For further studies on eggplant, it is strongly recommended that larger number of RAPD primers should be employed in revealing true genetic diversity of the crop. Larger sample size may also be used which may be collected from more distant locations. This may yield a more reliable and valid information on the crop. After all, no comprehensive assessment has been performed on the comparative diversity and regional differentiation of eggplant materials from different regions of the world (Hurtado et al., 2012). Highly polymorphic RAPD markers may even be applied in combination with other primers such as AFLP and ISSR in the molecular characterization of eggplant. Though a more cost effective and rapid technique of detecting polymorphism, RAPD markers have been noted for being dominant as they cannot distinguish heterozygous loci coupled with non-reproducibility of results. Notwithstanding, the RAPD approach used in the characterization of eggplant in this region can be described as a gigantic step in the genetic analysis of the crop.

In conclusion, the three species of eggplant investigated have displayed high level on intraspecific and interspecific variability as elucidated in the clustering patterns. The genetic relatedness among the species is substantiated by a sharp band on locus number 5 common to all the accessions in the multiplex band profile. The level of dissimilarities displayed by certain accessions on the other hand calls for more taxonomic audit and nomenclatural assignments. This is because such divergent members of a particular species such as the gilo group of S.aethiopicum gilo (PL3) and striped Gilo-Kumba complex (BN1A) may be named systematically. The results of this investigation are also relevant for the management of genetic resources, breeding programmes, and evolutionary studies of eggplant. This study has also contributed to the global biodiversity information system and the need for conservation of eggplant genetic resources in Nigeria where rare genotypes exist and this study may be extended to include other parts of Africa. The collection of eggplant from different locations undertaken in this study has successfully yielded a germplasm or gene bank consisting of 25 accessions of genetically diverse 
eggplants that can be explored for further studies. The use of exotic germplasm in breeding programmes can be of great relevance for the improvement of the crop and for addressing future breeding challenges (Hurtado et al., 2012). Eggplants therefore present a high morphogenetic potential that is useful for taxonomic studies and plant breeding programmes.
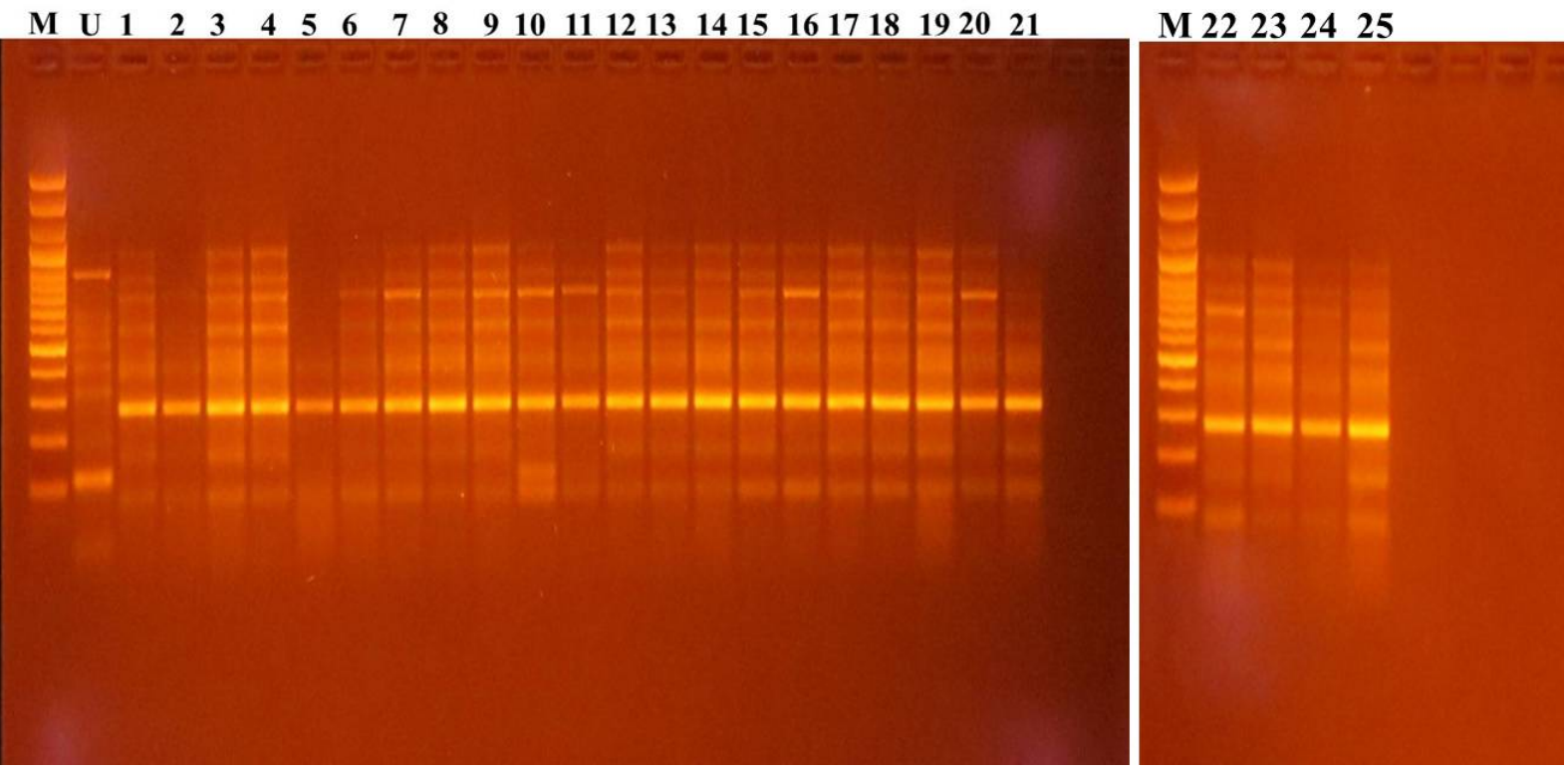

M U 123456789101112131415161718192021

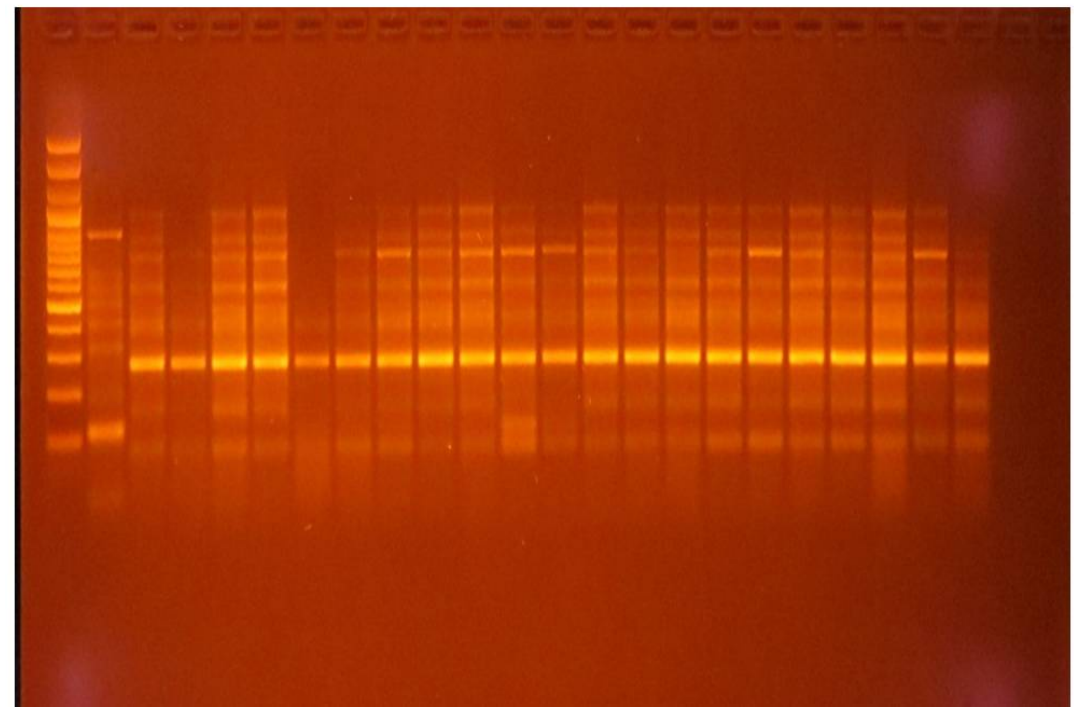

Figure 1. DNA band profile of multiplex primer

Legend: $\mathbf{M}$ represents 100bp ladder. $\mathbf{U}$ represents a control ladder. Number 1-25 indicate DNA bands of accession 1 to 25 respectively. 


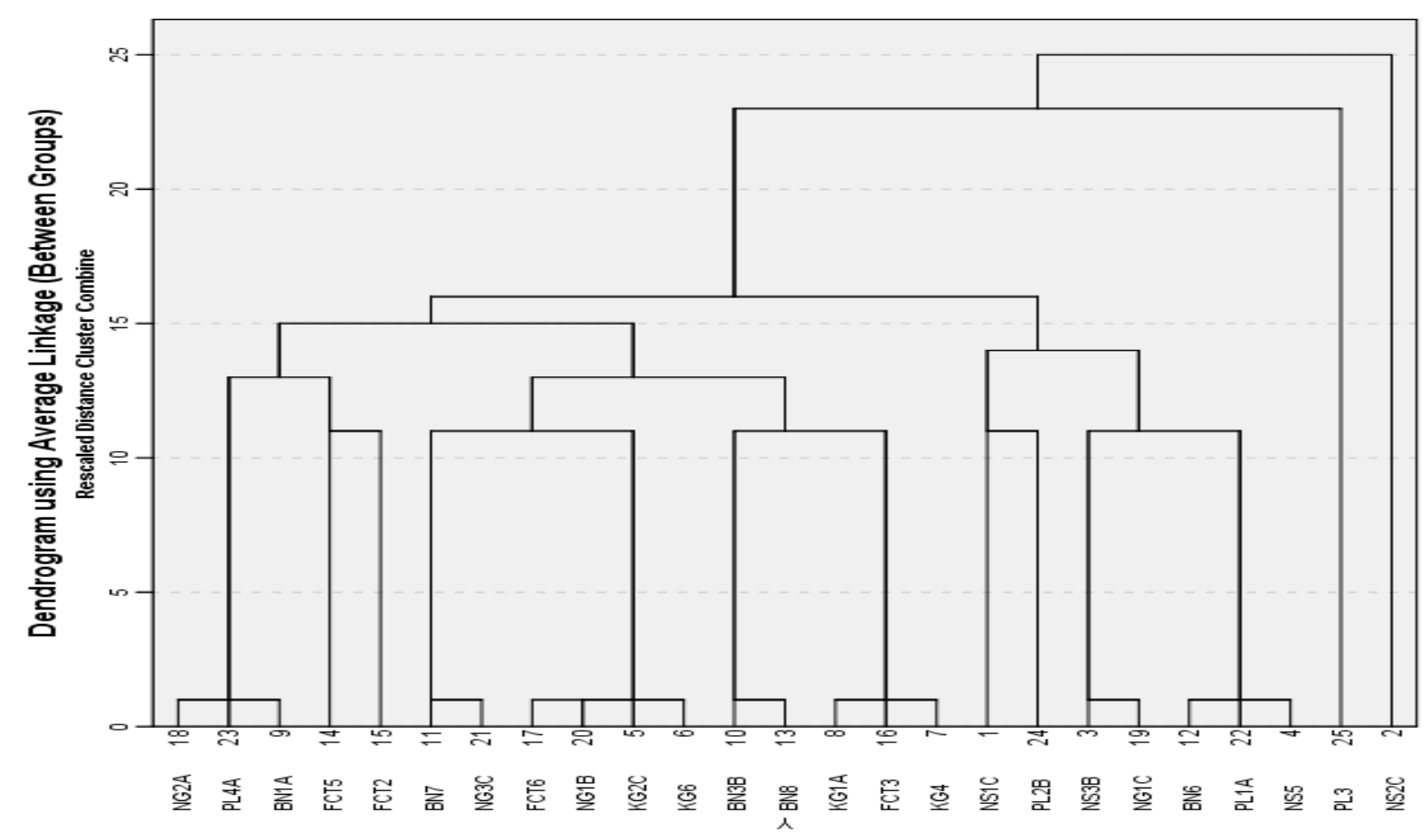

Figure 2. Dendrogram generated by OPQ 07 primer

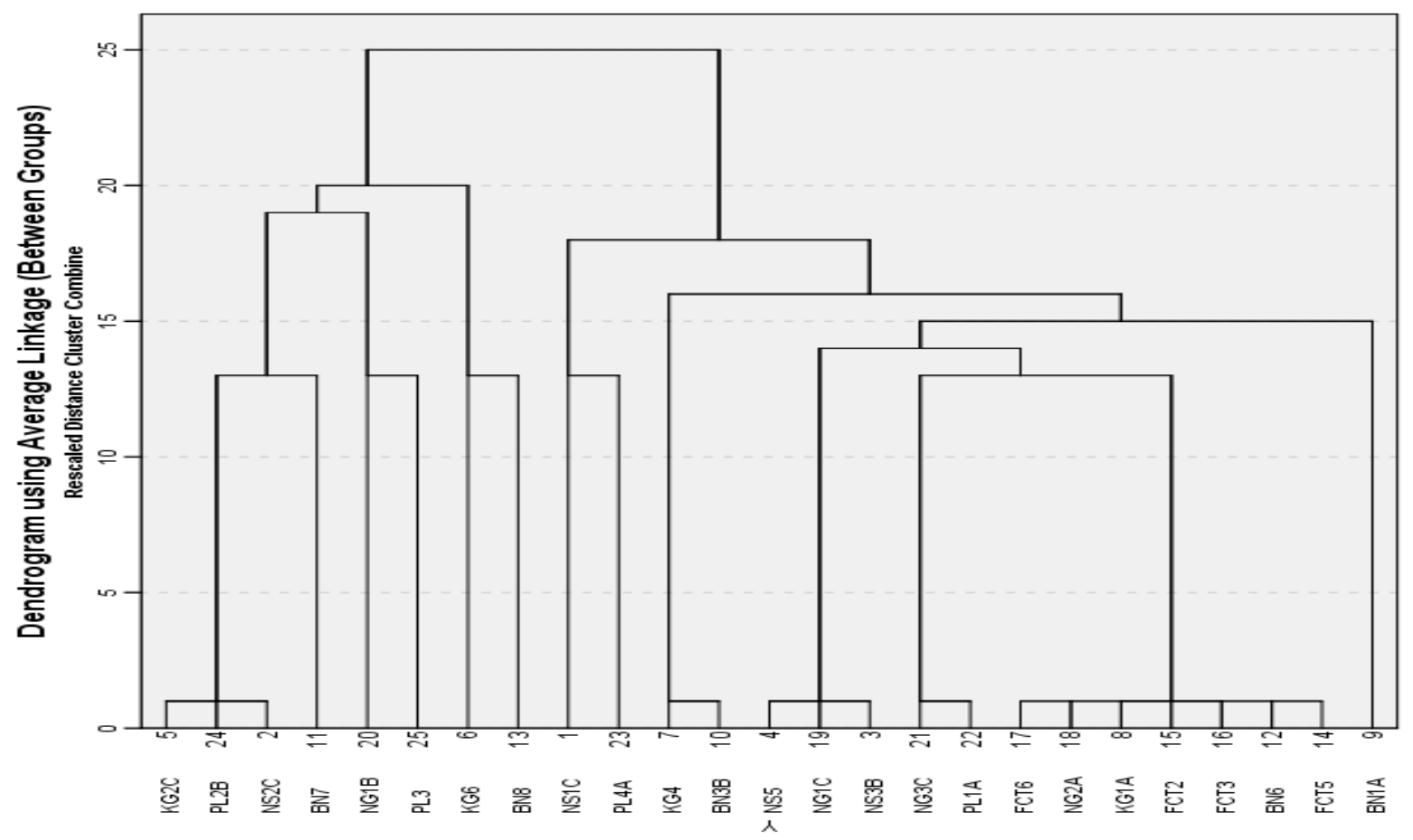

Figure 3. Dendrogram generated by multiplex primer 
Table 2. Primers and their polymorphic potentials

\begin{tabular}{llccc}
\hline Primer name & Sequence & $\begin{array}{l}\text { Mean number of } \\
\text { loci per band }\end{array}$ & $\begin{array}{l}\text { Mean number of } \\
\text { polymorphic loci }\end{array}$ & $\begin{array}{l}\text { Percentage polymorphic } \\
\text { loci }\end{array}$ \\
\hline $\begin{array}{l}\text { OPQ-07 } \\
\text { Multiplex of }\end{array}$ & CCCCGATGGT & 10 & 4.5 & $45 \%$ \\
OPP-11 & AACGCGTCGG & & & $45 \%$ \\
B-18 & CCACAGCAGT & & 4.5 & \\
OPU-13 & GGCTGGTTCC & 10 & & $\mathbf{4 5 \%}$ \\
OPU-15 & ACGGGCCAGT & & $\mathbf{9}$ & \\
Total & & $\mathbf{2 0}$ & & \\
\hline
\end{tabular}

\section{Reference}

Agnieszka, S., Stanisław, C., \& Kunicki, E. (2007). Cultivated eggplants - origin, breeding objectives and genetic resources, a review. Annal of Folia Horticulture, 19(1), 197-114.

Demir, K., Bakır, M., Sarıkamış, G., \& Acunalp, S. (2010). Genetic diversity of eggplant (Solanum melongena) germplasm from Turkey assessed by SSR and RAPD markers. Genetics and Molecular Research, 9(3), 1568-1576. http://dx.doi.org/10.4238/vol9-3gmr878

Furini, A., \& Wunder, J. (2003). Analysis of eggplant (Solanum melongena)-related germplasm: morphological and AFLP data contribute to phylogenetic interpretations and germplasm utilization. Theoretical and Applied Genetics, 108, 197-208. http://dx.doi.org/10.1007/s00122-003-1439-1

Hurtado, M., Vilanova, S., Mariola, P., Pietro, G., Fonseka, H., Fonseka, R., \& Prohens, J. (2012). Diversity and Relationships of Eggplants from Three Geographically Distant Secondary Centers of Diversity. Journal of Public Library of Science (PlosOne), 7(7), e41748.

Isshiki, S., Iwata, N., \& Khan, M. R. (2008). ISSR variations in eggplant (Solanum melongena L.) and related Solanum species. Journal of Science and Horticulture, 117, 186-190. http://dx.doi.org/10.1016/j.scienta.2008.04.003

Karihaloo, J. L., Kaur, M., \& Singh, S. (2002). Seed protein diversity in Solanum melongena L. and its wild and weedy relatives. Genetic Resources and Crop Evolution, 49(9), 533-539. http://dx.doi.org/10.1023/A:1021288108928

Khorsheduzzaman, K. M., Alam, M. Z., Rahman, M. M., Mian, M. A. K., Mian, M. I. H., \& Hossain, M. M. (2008). Molecular Characterization of five selected Brinjal (Solanum melongena L.) Genotypes Using SSR Markers. Bangladesh Journal of Plant Breeding and Genetics, 21(1). http://dx.doi.org/10.3329/bjpbg.v21i1.17041

Knapp, S., Vorontsova, M., \& Prohens, J. (2013). Wild Relatives of the Eggplant (Solanum melongena L.: Solanaceae): New Understanding of Species Names in a Complex Group. Journal of Public Library of Science (PlosOne).

Lester, R. N. (1998). Genetic resources of capsicum and eggplants. Xth EUCARPIA Meeting on Genetic and Breeding of Capsicum and Eggplant. 25-30, Avignon, France.

Mace, E. S., Lester, R. N., \& Gebhardt, C. G. (1999). AFLP analysis of genetic relationships among the cultivated eggplant, Solanum melongena L., and wild relatives (Solanaceae). Theoretical and Applied Genetics, 99, 626-633. http://dx.doi.org/10.1007/s001220051277

Mahmoud, M. I., \& El-Mansy, A. B. (2012). Molecular Identification of Eggplant cultivars (Solanum melongena L.) using ISSR Markers. Journal of Applied Sciences Research, 8(1), 69.

Mariola, P., Isabel, A., Santiago, V., Pietro, G., Javier, F., \& Prohens, J. (2014). Conventional and phenomics characterization provides insight into the diversity and relationships of hypervariable scarlet (Solanum aethiopicum L.) and gboma (S. macrocarpon L.) eggplant complexes. Frontier in Plant Science: Journal of Crop Science and Horticultue, 5, 1-13. 
Nunome, T., Suwabe, K., Iketani, H., \& Hirai, M. (2003). Identification and characterization of microsatellites in eggplant. Journal of Plant Breeding, 122, 256-262. http://dx.doi.org/10.1046/j.1439-0523.2003.00816.x

Osei, M. K., Banful, B., Osei, C. K., \& Oluoch, M. O. (2010). Characterization of African Eggplant for Morphological Characteristics. Journal of Agricultural Science and Technology, 4, 33-38.

Oyelana, O. A., \& Ugborogho, R. E. (2008) .PhenotypicvariationofF1andF2 populations from three species of Solanum L. (Solanaceae). Africa Journal of Biotechnology, 7, 2359-2367.

Sharmin, D., Khalil, M. I., Begum, S. N., \& Meah, M. B. (2011). Molecular Characterization of eggplant crosses by using RAPD Analysis. International Journal of Sustainability and Crop Production, 6(1), 22-28.

Sifau, M. T., Ogunkanmi, L. A., Adekoya, K. O., Oboh, B. O., \& Ogundipe, O. T. (2014). Partitioning and distribution of random amplified polymorphic DNA (RAPD) variation among eggplant Solanum L. in Southwest Nigeria. International Journal of Genetics and Molecular Biology, 6(1), 1-7. http://dx.doi.org/10.5897/IJGMB2013.0089

Smulders, M. J. M., Bredemeijer, G., Rus-Kortekaas, W., \& Aren, P. (1997). Use of short microsatellites from database sequences to generate polymorphisms among Lycopersicon esculentum cultivars and accessions of other Lycopersicon species. Theoretical and Applied Genetics, 97, 264-272. http://dx.doi.org/10.1007/s001220050409

Stagel, A., Portis, E., Toppino, L., \& Rotino, G. L. (2008). Gene-based microsatellite development for mapping and phylogeny studies in eggplant. BMC Genomics, 9, 357. http://dx.doi.org/10.1186/1471-2164-9-357

Whatman ${ }^{\circledR}$. (2014). Protocol on Plant DNA extraction using FTA Plantsaver method.

\section{Copyrights}

Copyright for this article is retained by the author(s), with first publication rights granted to the journal.

This is an open-access article distributed under the terms and conditions of the Creative Commons Attribution license (http://creativecommons.org/licenses/by/3.0/). 